\section{AB0421 MANAGEMENT OF ULCERATION IN SYSTEMIC SCLEROSIS BY A SPECIALIST PODIATRY SERVICE; A CASE SERIES}

L. Parker ${ }^{1}$, R. Field2, J. Marks'. ${ }^{1}$ University Hospitals Dorset NHS Foundation Trust, Rheumatology Department, Christchurch, United Kingdom; ${ }^{1}$ University Hospitals Dorset NHS Foundation Trust, Rheumatology Department, Christchurch, United Kingdom

Background: Systemic sclerosis is a chronic disorder characterised by diffuse fibrosis and vascular abnormalities in the skin and major organs. Digital ulceration is a common complication, often resulting in patient disability. These ulcers can form through a variety of processes and management should be tailored according to aetiology. In Dorset, the specialist podiatry service has created a unique facility for optimal wound care in the setting of digital ulceration.

Objectives: In this case series, we outline podiatric management of 4 common causes of digital ulceration in systemic sclerosis.

Methods: Tissue ischaemia, infection, micro-trauma and calcinosis were identified as four major contributory factors resulting in ulceration or delayed wound healing. Four cases exemplifying management of each different contributory factor were identified and their case notes reviewed in order to extract clinically relevant data and images.

Results: Case 1 illustrates treatment of ischaemic tissue injury to promote earlier healing, using careful wound care, debridement under local anaesthetic and lowlevel laser therapy.

Case 2 illustrates the importance of identifying repeated micro-trauma as a contributing factor to non-healing ulceration.

Case 3 demonstrates how surgical debridement or removal of the subcutaneous calcinosis in an outpatient setting can be a useful adjunct in encouraging ulcer healing.

Case 4 illustrates the complexity of correctly identifying infection in the setting of ulceration, with prompt management promoting wound healing.

Conclusion: The pathophysiology of ischaemic tissue damage in scleroderma is complex and can reflect a broad range of vascular pathologies, often occurring concurrently ${ }^{1}$ including vasospasm, macrovascular disease and microvascular vasculopathy, leading to digital ulceration. Rapid identification of which processes are driving the ischaemia is critical in targeting therapy to the affected individual. A local podiatry service with expertise in management of tissue -related complications of systemic sclerosis is invaluable in promoting wound healing and preventing further complications.

REFERENCES:

[1] Hughes M, Herrick A L. Digital ulcers in systemic sclerosis. Rheumatology 2017; 56(1):14-25.

Disclosure of Interests: None declared

DOI: 10.1136/annrheumdis-2021-eular.1276

\section{AB0422 DIAGNOSTIC PERFORMANCE OF THE ACR/EULAR 2013 CLASSIFICATION CRITERIA FOR SYSTEMIC SCLEROSIS IN A ROUTINE CARE SETTING}

M. T. Schiaffino ${ }^{1}$, B. Serrano-Benavente ${ }^{2}$, M. DI Natale ${ }^{1}$, K. Carpio ${ }^{2}$, J. MartínezBarrio $^{2}$, P. Sanchez-Mateos ${ }^{1}$, J. M. Alvaro-Gracia ${ }^{2}$, I. Castrejón Fernández ${ }^{2}$. ${ }^{1}$ Hospital Gregorio Marañón, Immunology, Madrid, Spain; ${ }^{2}$ Hospital Gregorio Marañón, Rheumatology, Madrid, Spain

Background: An ACR/EULAR task force released new criteria in 2013 to classify patients with systemic sclerosis (SSc).

Objectives: This study evaluates the diagnostic performance of these criteria in a multidisciplinary care setting.

Methods: Patients with an active follow-up in a Systemic Autoimmune Diseases Unit with a clinical diagnosis of SSc were matched by age and gender with consecutive patients referred to a capillaroscopy clinic. The classification criteria were tested on discrimination and diagnostic accuracy between both groups of patients defined as cases-SSc and controls. Receiver operating characteristic (ROC) curve and the area under the curve (AUC) was calculated for the global score to define the best cut off to classify the patients as having SSc.

Results: A total of 130 patients with SSc and 130 matched-controls were included in this analysis, $90 \%$ women, with a mean age of 61.5 . Main diagnosis for the control groups were primary Raynaud's phenomenon (34.6\%), undiferentiated connective tissue disease (13.1\%), and mixed connective tissue disease $(9.2 \%)$. The $92 \%$ and $8 \%$ of patients in the SSc-cases and control groups met the 2013 ACR/ EULAR SSc classification criteria respectively. Sensitivity and specificity of the criteria were $81.5 \%$ and $93.7 \%$, respectively. The best cut offs for the total score were 8 and 9 , and the AUC $(95 \% \mathrm{Cl})$ was $0.962(0.939-0.985)$. The individual items with a better discriminatory capacity were abnormal capillaroscopy, telangiectasia and anticentromere antibody positivity.
Table 1. Demographic data and ACR/ EULAR SSc classificacion criteria of SSC patients and controls.

\begin{tabular}{|c|c|c|c|}
\hline & Cases-SSc, $n=130$ & Controls, $n=130$ & $\mathbf{p}$ \\
\hline Age, mean (SD) & $62.4(16.0)$ & $61.3(14.8)$ & 0.58 \\
\hline Female, \% & 90.5 & 90.8 & 0.92 \\
\hline $\begin{array}{l}\text { Disease duration from onset of symptoms, } \\
\text { mean (SD) }\end{array}$ & $7.5(6.4)$ & $7.8(6.7)$ & 0.73 \\
\hline \multicolumn{4}{|c|}{$\%$ Patients with individual ACR/EULAR 2013 Criteria Items } \\
\hline Skin thickening & 15.8 & 0.7 & $<0.001$ \\
\hline Sclerodactily & 45.5 & 6.1 & $<0.001$ \\
\hline Puffy fingers & 27.7 & 1.5 & $<0.001$ \\
\hline Digital tip ulcers & 30.2 & 5.3 & $<0.001$ \\
\hline Fingertip pitting scars & 18.8 & 4.6 & 0.001 \\
\hline Telangiectasia & 51.5 & 6.1 & $<0.001$ \\
\hline Abnormal nailfold capillaries & 79.4 & 0.8 & $<0.001$ \\
\hline Pulmonary Arterial Hypertension & 16.3 & 3.8 & 0.001 \\
\hline Pulmonary fibrosis & 18.8 & 6.2 & 0.002 \\
\hline Raynaud's phenomenon & 90.7 & 66.9 & $<0.001$ \\
\hline Anticentromere antibody & 60.7 & 18.9 & $<0.001$ \\
\hline Scl70 & 12.0 & 0 & $<0.001$ \\
\hline Total Score & $12.5(4.8)$ & $3.4(2.9)$ & $<0.0001$ \\
\hline
\end{tabular}

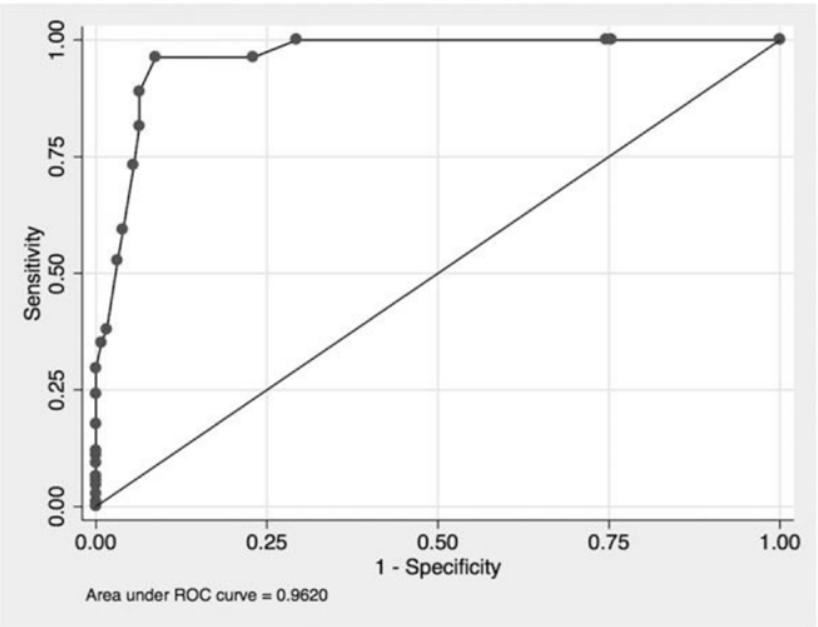

Figure 1. ROC curve for global score of the ACR/EULAR2013 SSc classification criteria.

Conclusion: The ACR/EULAR 2013 criteria showed good diagnostic properties in this cohort reflecting daily practice. Individual items showing the highest discriminatory capacity were abnormal capillaroscopy, telangiectasia and anticentromere antibody positivity.

REFERENCES:

[1] van den Hoogen F, Khanna D, Fransen J, et al. 2013 classification criteria for systemic sclerosis: an American college of rheumatology/European league against rheumatism collaborative initiative. Annals of the Rheumatic Diseases 2013;72:1747-1755

Disclosure of Interests: None declared

DOI: 10.1136/annrheumdis-2021-eular.1318

\section{$\mathrm{AB} 0423$ \\ SAFETY AND TOLERABILITY OF RITUXIMAB IN THE TREATMENT OF SYSTEMIC SCLEROSIS: LONG-TERM FOLLOW-UP}

L. Garzanova ${ }^{1}$, L. P. Ananyeva ${ }^{1}$, O. Koneva ${ }^{1}$, O. Desinova ${ }^{1}$, O. Ovsyannikova ${ }^{1}$, M. Starovoytova ${ }^{1}$, R. Shayakhmetova ${ }^{1}$, S. Glukhova ${ }^{2}{ }^{1}$ VA Nasonova Research Institute of Rheumatology, Laboratory of Microcirculation and Inflammation, Moscow, Russian Federation; ${ }^{2}$ VA Nasonova Research Institute of Rheumatology, Educational and Methodical Department, Moscow, Russian Federation

Background: Rituximab (RTX) has been used for the treatment of systemic sclerosis (SSc) for a long time, but data on tolerance and long-term adverse events $(\mathrm{AE})$ are insufficient.

Objectives: To assess the tolerability and safety of RTX in the patients (pts) with $\mathrm{SSc}$ in long-term prospective follow-up.

Methods: Data on the safety and tolerability of RTX were evaluated in 149 SSc pts who received at least one RTX infusion in a long-term open-label prospective observational study. The mean age was $48 \pm 13,5$ years (17-74), women - $122(82 \%)$, diffuse cutaneous subset of the disease had $52 \%$, limited-37\% and overlap- $11 \%$. 